\title{
Research on the Construction of Literature Information Resources in University Libraries under the Background of Big Data
}

\author{
XiuHua Ma and GeMin Li \\ Jilin Agricultural University Library, Changchun, China
}

\begin{abstract}
Key words: Big data; University library; Information resources construction
\end{abstract}
\begin{abstract}
With the development and popularization of information technology, big data has become a hot topic among scholars. In the past dozens of years, big data had penetrated into every aspect of the society and had been widely applied. In order to adapt to the trend of information technology, the construction of literature information resources in university libraries should be changed under the background of big data. How to make full use of information resources to provide better services to students has become a problem that library management personnel must solve.
\end{abstract}

\section{Introduction}

The collection resources of university libraries are the material basis for existence of libraries. At present, as many as 50000 to 60000 volumes of new books are published every year in China, the surging volumes of new publications has brought a lot of pressure on university libraries. On one hand, the prices of new books are comparatively high, and this can easily lead to the shortage of funds for libraries. On the other hand, the libraries have not enough space to store more books. Under such background, it is necessary to build the information resources of university libraries with the support of big data technology.

\section{Problems for Construction of Literature Information Resources in University Libraries}

\section{A. High Degree of Repeatability for Literature Information Resources}

The information resources construction started relatively very late in China; due to the lack of strict management and control policies for information resources, a lot of data providing merchants competed adversely with each others for their own interest, so the data provided by them has very high degree of repetition rate. Now, many databases that are known among teachers and students, such as: Vepsa, HowNet, Wanfang Data, have a lot of repetitive data, and even duplicate content exists in some electronic books, video data and dissertations; this can easily lead to the waste and unreasonable use of resources.

B. Shortage of Funds for Literature Information Resources

In some key universities in China, some universities can receive support and supplementary funds from the government, all sorts of funds are relatively adequate, and the construction of talents and resources is also relatively perfect. However, in recent years, the surge of domestic and foreign publications and the continuous increase of major website resources formed striking contrast with imperfect hardware information equipments of most of the university libraries; this became worse for those universities that had been suffering shortage of funds. According to statistics, in 2009, among over 70 colleges and universities in Liaoning province, 1/4 universities did not have their own websites and databases; this phenomenon more obviously showed that the colleges and universities libraries in China have not sufficient investment for information construction.

C. Stereotyped Information Resources Allocation without Distinction

Due to the different levels of colleges and universities, their types are different, and they're subject to the constraints of various conditions and funds, which can easily lead to the stereotyped allocation of information resources and lack different characteristics. First, the majority of the resources stored in the university databases are purchased from the data retailers, and the universities lack the construction of information resources with their own characteristics. Second, 
most of the data stored in the databases are general information resources, and they lack the construction of characteristic resources. Third, the resources stored in the database are most academic research content, and very few resources can be used in teaching. Fourth, each university database is built by itself, and the database lack resource sharing.

D. Lack of Professionals for Construction of Information Resources

The construction of university libraries information resources in China started relatively very late, and the development was not perfect and the lack of related professionals is a prominent problem. Now, it has become the major trend for the universities to develop and construct their own characteristic database; it is one of the important signs for a competitive library to construct a powerful database. Due to the position of libraries in universities and the constraints of its working nature, it's very difficult for university libraries to introduce digital processing technology, database technology, storage and retrieval technology and Internet technology, the professionals of information technology can hardly be attracted. In this case, the database construction of university libraries is seriously restricted. In addition, due to the lack of management system, the librarian lacks the awareness and motivation of further learning, so the libraries lack inter-disciplinary talents and this also restricts the development and information construction of libraries.

E. Standards and Services of Information Resources Construction

The information resources construction should follow the unified standards and norms; in order to facilitate the exchange and concentration of information resources in the construction process, and further facilitate the convenient use and retrieval for users, data providers should follow the standards in "Construction of Annotation Standard for Digital Libraries in China" to construct and improve the university libraries. In the construction process, we should use the maturity standards of CDSL as far as possible. The data provider should establish the operation philosophy of "reader first", and strictly control the after-sales service, timely solve various problems that the readers encounter in their use, timely supplement the knowledge and data, and correct the discovered errors on a timely basis. The data providers should create a convenient, fast and accurate reading environment for readers.

\section{Information Resources Construction Measures for University Libraries under the Background of Big Data}

\section{A. Promote Sustainable Development of Information Resources}

The construction of information digital library is a construction process of information resources as a whole, and it can realize the continuous sharing of information resources in the global scope. The government should increase investment and provide sufficient fund support for the construction of information resources in university libraries, and refer to the domestic and foreign advanced construction experience; the universities should, on the basis of the actual needs of the teachers and students, have an overall planning, and try to avoid waste of fund and resources due to repetitive construction. Through the joint purchasing method, the university libraries should introduce the database with high degree of versatility, so as to effectively alleviate the pressure on funds. At the same time, the database resources with high degree of versatility can also improve the utility efficiency and service levels of information resources.

Simply from the perspective of service resources market value, we know that it common-construction and sharing is the effective way to achieve scale economic benefits; at the same time, it can also strengthen its own competitive ability to remain invincible in the fierce market competition for a long time.

\section{B. Construct Characteristic Information Resources Library}

The construction of information resources in university libraries should be practical, both for collecting books and collecting data, so as to serve the readers. The purpose of constructing university libraries is to provide information query and assistant study to teachers and students and serve the scientific research projects of universities. Therefore, the construction of resources should be closely based on the actual situation of the university, to meet the needs of the university's 
specialty and disciplinary construction. The collecting of literature data should follow the principles of characteristics and high quality, and the literature should be complete and characteristic. First, we should increase our efforts in construction of precious resources and characteristic resources. Second, we should pay more attention to the construction of resources that are significant for teaching. Third, the university should strengthen the construction of excellent dissertations; fourth, we should focus on the construction of information resources with independent intellectual property rights. In addition, in the process of information resources construction, we should strengthen the planning and construction of characteristic database of university libraries.

If two or more universities or colleges are located in nearby area or have similar or the same subject contents, they can cooperate to construct a combined characteristic database to share data resources and learn from each other.

\section{Focus on Processing and Use of Complicated Data}

The sum of structured data, semi-structured data and unstructured data is called big data. Big data is complicated, and only $1 / 10$ of the data is the structured data stored in the database, the majority of the other data is unstructured data and semi structured data generated by e-mail, video, WeChat and micro-blog. In our daily life, the data generated by intelligent devices and Internet are not structured data. We generate very little structured data in our daily work and study.

As the information exchange center of university, the university library must comprehensively master the characteristics, technology and application scope of large data and pay attention to the construction of structured resources, as well as pay some attention to the construction of unstructured resources and semi-structured resources. We should have the means of quickly excavating the information that students are interested in, and then recommend the information to students according to their hobbies and preferences. This will be the direction and key content for the future development of university libraries.

\section{Strengthen the Construction and Training of Information Talents}

We should establish perfect reward and punishment system for the original library staff, to reward the outstanding staff to stimulate their working initiative and enthusiasm, so the staff can serve the readers more actively; we should also create specific punishment system, to make the punishment more standardized, institutionalized and systematic, so the punishment behavior have correct orientation, the appraisal are based on rules and the inspection is well-grounded.

Establish the long-term goal and short-term goal of library development, so the library management personnel can participate in the development of the library, set up their own work goals and determine their working direction. The library should reward those who have achieved their goals and perform well; the rewards can be divided into two kinds: material reward and spiritual reward. The material reward is a type of substantive reward to staff with bonuses and subsidies. The spiritual reward is to circulate a notice of great performance of the staff through internal journals. The material and spiritual stimulation to the employees can stabilize the staff team and stimulate their work enthusiasm. Actively cultivate inter-disciplinary talents who are highly sensitive to computer and library knowledge and intelligence, to establish a strong team of information talents.

\section{E. Strengthen Construction of Information Resources System}

Comprehensively strengthen the construction of information resources and management system of university library; through the questionnaire survey and demonstration of teachers and students, on the basis of the utility situation of annual collection of books and databases, to analyze and determine the type of database to be purchased every year; implement dynamic management for the database construction, to clean up the database resources with very low utility and even no utility in time, to fully exert the utility value of the purchasing funds. At the same time, the construction of the database shall be linked with the performance and promotion of professional titles of the management personnel, so as to strengthen the construction of the library information resources system. 


\section{Conclusion}

The construction of information resources in university libraries cannot be completed overnight, nor is it possible for a single person or organization to complete. The construction of information resources in university libraries requires joint efforts to integrate resource construction and knowledge service. In the era of big data when opportunities and challenges coexist, the university libraries should grasp the pulse of the times to change the original mode of information resource construction, to construct a brand new university libraries literature information resources system under the background of big data. The university libraries should construct perfect information resources database, perfect consultant service window, perfect retrieval system and perfect after-sales service system for students. According to the principle of serving students with all resources, the university libraries should serve all the students.

\section{References}

[1] Zhao Jing. Problems in Construction of Literature Resources in University Libraries [J]. Journal of Library and Information Sciences in Agriculture, 2016, (05): 25-27.

[2] Miao Zhuo. Analysis on Problems in Construction of Digital Resources in University Libraries [J]. China Management Informatization, 2015, (24): 192-193.

[3] Xu Chunyan, Xu Lili, Hong Yanxia. Application of Big Data in Construction of Information Resources in University Libraries [J]. Journal of Library and Information Sciences in Agriculture, 2017, (02): 27-29. 